\title{
O PROBLEMA DA ESPACIALIDADE DA DEMOCRACIA E A AMPLIAÇÃO DA AGENDA DA GEOGRAFIA BRASILEIRA
}

\section{The Issue of Democracy Spatiality and the Expansion of the Brazilian Geographic Agenda}

Profa. Dra . Iná Elias de Castro

Prédio do CCNM, Bloco I, Sala 20, Cidade Universitária, CEP. 21945-970 - Ilhadora CNPq e FAPERJ Tel/Fax: (+55 21) 22707773 / 25901308 - inacastro@uol.com.br

\section{$a_{a} \boldsymbol{a}_{a a}$}

\begin{abstract}
Resumo
O trabalho trata da espacialidade da democracia e de que modo as pesquisas da geografia brasileira podem contribuir para melhor qualificá-la. Tendo em vista o debate sobre a reforma política no Brasil, busca-se temas novos para ampliar a agenda da disciplina, incluindo-a no debate. O ponto de partida é a suposição de que há uma "natureza espacial" na democracia, como argumentado por Rousseau (1978), o que convida a geografia a refletir sobre o tema. A assertiva é a impossibilidade de pensar a política submetendo-a aos princípios da economia e sem refletir sobre suas instituições e a inserção destas no espaço da sociedade. O texto está organizado em duas partes: a primeira propõe uma breve discussão sobre a espacialidade da democracia, incorporando-a a agenda da geografia; a segunda apresenta alguns argumentos sobre a importância da experiência democrática brasileira nas últimas décadas e as transformações que ela favorece no país.
\end{abstract}

Palavras-Chave: Esapacialidade, democracia, geografia.

\begin{abstract}
The following paper studies the spatial character of democracy and explores ways in which research in Brazilian Geography can contribute to better understand it. Having the debate about political reform in Brazil in view, the paper seeks to find new themes to amplify the agenda of the discipline, including it in the debate. The point of departure is the supposition that there is a "spatial nature" in democracy as argued by Rousseau (1978), which invites geography to reflect on the theme. The paper posits that it is impossible to think about politics only within the confines of economic principles, without reflecting on its institutions and their insertion in societal space. The text is organized in two parts: the first offers a brief discussion about the spatial character (spatiality) of democracy, incorporating it into the geographic agenda; the second introduces some arguments about the importance of the Brazilian democratic experience in these last decades and the transformations that it influences in the country.
\end{abstract}

Key Word: Spatial character, democracy, geography.

\section{Résumé}

Ce texte porte sur la spatialité de la démocratie et la manière dont les recherches géographiques sont capables de la qualifier. En vue du débat sur la réforme politique au Brésil, on essayera de montrer comment la géographie peut s'y inscrire, tout en relevant les sujets novateurs capables d'élargir l'agenda de recherches de cette discipline. On part de l'idée selon laquelle la démocratie présente une nature éminemment spatial, tel que cela fut proposé par Rousseau (1978) ; ce principe invite donc les géographes à réfléchir sur le sujet. L'assertive est celle de l'impossibilité de penser la politique lorsqu'elle est soumise aux principes de l'économie, et sans qu'une réfléxion sur ses institutions et l'insertion de ces dernières dans l'espace des sociétés soit faite. Le texte est organisé en deux parties : la première propose un débat à propos de la spatialité de la démocratie qui rattache cette dernère à l'agenda de la géographie ; la deuxième présente un certain nombre d'arguments sur l'importance de l'expérience démocratique au Brésil pendant les dernières décennies et les changements favorables qui en découlent.

Mots- Clé: spatialité, démocratie, géographie. 


\section{INTRODUÇÃO}

Em tempos de discussão para reformas políticas no Brasil, especialmente a do nosso sistema eleitoral, me parece que a geografia teria algo a dizer. Este é o momento de avançarmos temas novos para a ampliação da agenda da disciplina e da sua contribuição ao debate político no país. O ponto de partida aqui é colocar em evidência o problema da espacialidade e da socialidade da democracia e de que modo as pesquisas da geografia brasileira podem contribuir para melhor qualificá-lo, dentro da proposta de Um projeto político para o Brasil: geografia e mudança social.

Para evitar quaisquer veleidades de opinião, afinal os temas política e democracia podem facilmente derivar para convicções pessoais e partidárias que, apesar de excelentes motivos para discussões em saraus ou na mesa do bar, pouco tem de acadêmico e não são a melhor maneira de enfrentar o tema na pesquisa. $O$ que não quer dizer que pesquisadores não tenham convicções políticas e utopias e que não devam lutar por elas, mas há que distinguir o ofício do pesquisador daquele do ativista. Afinal de contas, o papel do pesquisador é enunciar perguntas que expressam dúvidas que devem ser enfrentadas pelo árduo trabalho de investigação da realidade, o ativista ao contrário se coloca a certeza de um caminho de ação que deve ser trilhado. Da mesma forma que a dúvida é um entrave à ação, a certeza é a pior conselheira da pesquisa acadêmica.

O ponto de partida aqui é a suposição de que há uma "natureza espacial" na democracia, como argumentado por Rousseau (1978), o que convida a geografia ao debate, tendo em vista a autonomia do poder político como ressaltado por Michael Mann (1992). Donde a assertiva de que não é possível pensar a política submetendo-a aos princípios da economia e sem refletir sobre suas instituições e a inserção destas no espaço da sociedade. A apresentação que se segue está organizada em duas partes e propõe discutir os limites epistemológicos da submissão das ordens social e espacial àqueles princípios da ordem econômica e reforçar o nexo entre a institucionalidade da política e o território. A primeira parte propõe uma breve discussão sobre a espacialidade da democracia e se insere na corrente contemporânea que a incorpora à agenda da geografia. O objetivo é destacar algumas questões que vem emergindo na disciplina no sentido de debater o problema mais amplo da dimensão geográfica da política e de que modo as matrizes intelectuais da geografia enfrentam a democracia como problema conceitual e como modelo institucional. Na segunda parte, serão apresentados alguns argumentos sobre a importância da experiência democrática brasileira nas últimas décadas e as transformações que ela favorece no país.

\section{DEMOCRACIA E GEOGRAFIA - PROBLEMA CONCEITUAL E MODELO INSTITUCIONAL}

A discussão em torno da idéia de democracia como forma de governo é fascinante e desafia a geografia a participar mais ativamente dela. Seja pelo debate teórico que desde a antiguidade anima as melhores mentes; seja pelas tentativas de colocá-la em prática e a polêmica sobre os formatos institucionais mais adequados; seja porque sua existência (ou ausência) afeta o cotidiano das sociedades; seja pela sua expansão, desde a década de 1990, por um número crescente de países; seja porque a democracia não pode ser pensada sem considerar a geografia. Esta pretensão corporativa merece esclarecimento. Se partirmos do suposto de que a democracia é uma forma de governo, este necessariamente implica considerar a sociedade e o território e, conseqüentemente, questões como: extensão, distância, acessibilidade, escala, população, densidade, infra-estrutura, urbanização, estrutura social etc.

Como forma de governo, o caráter específico da democracia é mais bem compreendido nas relações com as outras formas estabelecidas (BOBBIO, 1985), especialmente na oposição histórica com a monarquia, a aristocracia e a tirania e na atualidade no confronto mais radical com o autoritarismo e com o totalitarismo (LEFORT, 1983). Mas há que ressaltar também que a democracia é formato político e prática social, e como tal contextualizada nos espaços e nos tempos das diferentes sociedades que a adotam, o que justifica a farta literatura sobre ela. Paralelamente, as diferentes 
perspectivas adotadas desenvolvem argumentos tanto a favor como contra os seus princípios e sua aplicação, o que sinaliza a necessidade de debatê-los. No entanto, é indispensável assumir como ponto de partida que não se trata de um formato à moda da casa, reinventado ao sabor de pessoas e lugares, mas ao contrário, chamar a atenção para a necessidade de uma definição clara e mínima do que seja uma forma de governo democrático, capaz de diferenciá-lo da tirania, do autoritarismo, do totalitarismo e da violência institucionalizada.

Como primeira aproximação, impõe-se então considerar o incessante debate, em diferentes contextos, sobre os formatos institucionais mais adequados para fazê-la funcionar e sobre as críticas, sempre renovadas, a eles dirigidas. O debate está longe de esgotar-se e ancora-se, na atualidade, nos prospectos necessários para alcançar liberdade e justiça; ou seja, naquelas condições objetivas que conduzam a uma sociedade livre e justa, onde a realização dos projetos de um indivíduo não reduza o estoque disponível para a realização dos projetos de quaisquer outros membros da sociedade como conteúdos inescapáveis da percepção contemporânea de democracia como um valor universal (RAWLS, 2004; SANTOS, 2007; LEFORT, 1983; BOBBIO, 1995; TOURRAINE, 1999).

O debate contemporâneo sobre a democracia envolve, pois questões importantes sobre os formatos institucionais mais adequados aos objetivos de aproximação da sociedade com as decisões do governo. A discussão sobre a efetividade e a legitimidade da representação política é uma dimensão desse debate que, no limite, opõe os modelos de democracia representativa e de democracia direta. Estes modelos, debatidos desde o iluminismo, tinham em suas formulações evidentes dimensões espaciais. A democracia direta de Péricles dificilmente poderia ser reproduzida nas extensões territoriais dos estados europeus, mas seu espírito permanecia na incessante procura pelo formato institucional que melhor representasse a vontade do cidadão.

Neste sentido, o problema central do debate em torno da democracia na atualidade permanece a clivagem sobre a melhor forma de governo capaz de alcançar o bem comum, o que opõe duas condições: a da democracia representativa, para a qual é central o problema dos aparatos institucionais que garantam a vontade da maioria da população, embora respeitando os direitos e a livre expressão das minorias; e a vertente da democracia radical ou direta, cujo problema central encontra-se na busca do consenso e eliminação do conflito. Esta oposição, presente na teorização da democracia, na geografia atual assume um caráter muito particular na medida em que remete ao problema da escala (CASTRO, 1995; COX, 1998; JUDD, 1998), da relação entre o particular e o geral (ENTRIKIN, 1997), da diferença da natureza do local e do global (BARNETT 2004; BARNETT e LOW, 2004) e que opõe as vertentes de inspiração marxista àquelas intelectualmente mais pluralistas (O’LOUGHLIN, 2001; BELL e STAEHELI, 2001; STOKKE, 2009; MOUFFE, 2000)

Esta aparente simplicidade esconde os termos opostos e, para alguns, inconciliáveis do debate que na geografia confronta os argumentos favoráveis à representação política como uma condição necessária às sociedades de massa contemporâneas e aqueles que defendem a democracia direta ou radical. No entanto, a convergência entre esses dois princípios não é impossível desde que a irredutibilidade da norma seja aceita (BARNETT, 2008) e que a força da solidariedade social desenvolva-se em espaços públicos autônomos, porém institucionalizados em termos do Estado de Direito (HABERMAS, 1995).

Estas duas visões do mundo social vem de matrizes filosóficas diferentes e conduzem, grosso modo, a duas formulações de base para a democracia. Na primeira, é a forma de governo adequada às sociedades modernas, livres, urbanizadas e complexas, atravessadas por interesses muito diferenciados que requerem a centralidade territorial do poder, o Estado, para o gerenciamento dos conflitos que emergem de interesses individuais. Na segunda, trata-se de comunidades compostas por membros solidários cujo consenso é o cimento da sua própria existência que na maioria das vezes buscam autonomia frente ao Estado, ou mesmo contra ele; nesta condição tanto a liberdade de escolha individual como os conflitos são eliminados. Mas não deve ser ignorada a corrente ainda signatária da perspectiva marxista, focada nas questões da acumulação do capital e da luta 
de classes, que considera a democracia um epifenômeno e, portanto irrelevante. Discutiremos este ponto adiante.

Nas correntes da geografia humana crítica, alinhada com a matriz pós-marxista ou para a geografia humanista, alinhada com a fenomenologia, o espaço de contenção da democracia é o "lugar" (BARNETT, 2008). Este faz brotar uma comunidade onde o conflito de interesses é substituído pela identidade e pela disposição para cooperação e para a convivência pacífica (MASSEY, 1995:287; MOUFFE, 2000) cuja escolha de forma de governo recai sobre a democracia direta. No entanto, para as correntes da geografia de base epistemológica mais pluralista, não é possível na contemporaneidade procurar a democracia fora do seu lugar político de contenção institucional, isto é, o Estado, suas instituições e a sociedade (BARNETT e LOW, 2004:11; CASTRO, 2005).

Esta perspectiva remete à suposição da irredutibilidade de as instituições políticas do Estado sediarem o governo nas sociedades contemporâneas complexas. Não é de admirar, pois que no ambiente intelectual da geografia nas décadas de 1970 e 1980, fortemente influenciado pela crítica sociológica àquelas instituições, pela demonização do liberalismo e seus correlatos - o individualismo e o capitalismo - e pela reificação do poder, o tema da democracia, tenha sido marginal na agenda da disciplina.

Essa crítica não foi sem consequência para a agenda da geografia política. Smith (1996:76) chama a atenção para o fato de que "desde os últimos anos da década de $70,[\ldots]$ a noção de congruência territorial entre Estado e democracia foi amplamente questionada". Para ele, o problema central refere-se à crítica da teoria da soberania e sua presunção de que a nação-Estado seria o modo mais apropriado de assegurar um governo representativo e de proteger os interesses de seus cidadãos. Esta é a expectativa das democracias liberais, criticadas à direita do espectro político pelo crescimento exagerado das burocracias públicas, que reduziu o espaço da iniciativa privada e da responsabilidade individual, e à esquerda, pelo fato de o Estado estar inextricavelmente preso ao capitalismo e aos interesses das classes dominantes. Na geografia, a crítica ao Estado como um recorte consistente para a análise, tanto pelos alinhados com matriz intelectual liberal como os seus opositores, não foi sem conseqüência para a democracia como problema conceitual e empírico passível de ser apropriado pela disciplina.

Esse debate reflete a polêmica que desde o século XVIII se trava entre os pensadores sociais em torno do conceito de democracia e das possibilidades concretas de aplicá-lo às diferentes realidades sociais. É nesta perspectiva que Kariel (1970) reuniu, nos Estados Unidos, os argumentos sobre a democracia de diferentes teóricos e seus críticos. Seu ponto de partida para a tarefa era um aparente consenso, pois "logo após a Segunda Guerra mundial um amplo levantamento da UNESCO mostrou que o conceito de democracia era suficientemente elástico para agradar a todas as nações. Os princípios da democracia obtiveram aclamação universal" (op.cit.:ix). As trinta e uma leituras mostram as discordâncias sobre o lugar, significância e promessas da democracia na vida moderna. Mostram também que, sem serem explicitamente formuladas, diferentes teorias de democracia competem e impõem arranjos sociais diferentes. Ou seja, abraçar uma ou outra teoria da democracia supõe de fato estabelecer expectativas e modelos institucionais diferentes.

No entanto, o debate entre os ideais do autogoverno e a possibilidade do voto periódico em eleições livres como condição suficiente para a democracia aponta tanto a impossibilidade da democracia direta nas modernas sociedades de massa urbano industriais, como os limites do elitismo subsumido nas eleições como um ideal finalistico. Ou seja, nenhuma das duas fórmulas satisfaz per se uma definição mínima de democracia que seria o regime de governo em uma sociedade capaz de evitar a tirania da maioria e o poder de veto da minoria (SANTOS, 1999). Além disso, esse debate desloca a questão mais atual de como estabelecer dispositivos institucionais capazes de realizar os ideais de justiça social e liberdade implícitos nas modernas teorias da democracia (RAWLS, 1971, 2004).

Neste sentido, a democracia como problema para a pesquisa na geografia não se esgota na geografia eleitoral, tradição importante da disciplina, mas deve ir além, abrindo-se para as possibi- 
lidades dos ordenamentos espaciais em diferentes escalas que emergem dos arranjos institucionais da democracia, adotados por diferentes sociedades nacionais. Não parece, pois, possível pensar nos espaços da democracia sem refletir sobre os ideais e ideologias que subjazem nas diferentes opções políticas das sociedades. A democracia, na realidade, tem sido um problema intelectual da sociologia e da ciência política, mas seus fundamentos são filosóficos. Esta matriz intelectual, no entanto, não impede que a geografia se aproprie dessas reflexões uma vez que, como bem constatou Tocqueville (2005) em seu "Da democracia na América", o território faz diferença como componente do modelo político capaz de expressar a liberdade das aspirações individuais e coletivas. Por outro lado, a questão da distribuição territorial do poder político constitui na atualidade um dos principais temas da ciência política e da teoria democrática (LIJPHART, 1989), o que certamente favorece o diálogo da geografia com estas áreas de conhecimento.

Mas, para alguns geógrafos a questão não parece tão simples. Para Entrikin (2000:190), por exemplo, "os conceitos de teoria política e de geografia humana parecem incomensuráveis, ou seja, sem uma medida comum. Espaço e lugar se acomodam mal no discurso da teoria moderna da democracia". O autor faz exceção aos espaços públicos, aliás muito trabalhados recentemente na disciplina, e conclui que "em geral, a lógica do espaço e o espírito dos lugares são raramente centrais nos debates anglo-americanos sobre a teoria da democracia". Para ele, o problema reside no liberalismo individualista que não tem necessidade da geografia para além de um "continente espacial" para indivíduos atomizados. Outra explicação seria a distância entre as aspirações universalistas da teoria da democracia e a natureza particularizadora do conhecimento geográfico. Porém, a crítica de Entrikin decorre mais da experiência da democracia na sociedade norte-americana e da vertente cultural crítica focada no lugar que ele adota na geografia do que problemas específicos da teoria da democracia. Afinal, é tarefa dos geógrafos, estudiosos do espaço, decidir se a democracia, enquanto problema teórico e prática de algumas sociedades, deve ou não ser um objeto de reflexão relevante para a disciplina.

Na perspectiva deste debate, Bussi (2001) vai bem mais além, quando reconhece o distanciamento da geografia frente aos temas relativos à participação e à democracia, mas apresenta argumentos para uma necessária aproximação dos geógrafos a esses temas. O autor levanta seis hipóteses para esse distanciamento. As duas primeiras apontam tanto para o afastamento da geografia em relação à política como para o privilégio conferido às relações de poder em lugar das relações políticas. Seus argumentos, fundamentados na geografia francesa, apontam com pertinência o embaraço dos geógrafos frente ao papel de "conselheiro do Príncipe" que, em alguns casos, lhes era requisitado; bem como o privilégio conferido às questões geopolíticas, prerrogativa do que era então chamado de uma geografia do poder. As demais hipóteses levantadas pelo autor para justificar esse afastamento apontam também para a maior proximidade teórica da democracia com a ciência política e a sociologia e para a novidade do fato democrático. As duas últimas hipóteses elaboradas para justificar o afastamento da geografia em relação às questões da democracia, destacam a diferença entre os pontos de vista (ou abordagem) ascendente da democracia, ou seja, do indivíduo para a sociedade, e descendente da geografia, isto é, do ambiente, do contexto espacial para os indivíduos. Aqui sua posição é oposta a de Entrikin, indicada acima. Sua última hipótese para o afastamento é surpreendente e aponta para a real proximidade da geografia e da democracia, sugerindo que a distância entre elas é apenas aparente. O texto de Bussi é oportuno e reforça a importância do tema na agenda da disciplina. Seus argumentos sintetizam com clareza algumas das razões possíveis para a indigência intelectual da geografia política frente a um tema como a democracia, tão fundamental às sociedades contemporâneas e aos seus territórios. Mas o problema está longe de esgotado, há outras razões trazidas ao debate por outros autores.

Enriquecendo a discussão, os argumentos de Barnett e Low (2004:1) são contundentes e chamam a atenção para o silêncio da geografia quando se trata da democracia e da democratização como temas. Para os autores, nas últimas décadas do século XX, os geógrafos estiveram muito mais 
atentos ao debate sobre a globalização, o neo-liberalismo e as críticas ao capitalismo e não deram atenção à tendência global de proliferação de regimes democráticos. Como conseqüência, a democracia como teoria e como prática ficou esquecida pela disciplina. Diferente da hipótese de Bussi sobre a proximidade entre geografia e democracia como razão para a desnecessária explicitação da democracia como questão, uma vez que ela estaria subsumida em diferentes temas e questões da disciplina, aqueles autores falam numa presença fantasmagórica da democracia na geografia que pode ser ilustrada em três apontamentos. No primeiro, na mesma linha dos argumentos de Smith (1996) apresentados acima, o problema da crítica ao Estado capitalista, central aos trabalhos de inspiração marxista na disciplina desde a década de 1970 e continuados nas de 80 e 90 com a teoria da regulação, puseram em causa os conceitos de legitimidade e de representatividade das instituições do Estado. Neste sentido, a participação e a representação políticas permanecem periféricas, constrangidas pela conceituação do processo político como fundamentalmente derivado dos interesses econômicos. No segundo, a marginalização da democracia como tema na geografia apóia-se na preocupação com a justiça social. Os autores ressaltam que isto pode ser contra-intuitivo, uma vez que o valor da democracia como forma de governo é frequentemente vinculado ao seu papel de assegurar justiça social, como bem sustentou Rawls (1981). No terceiro, a marginalização da democracia decorre da pesquisa recente sobre as geografias da cidadania e nos discursos sobre pertencimento e identidade que emergem dos problemas mais recentes da imigração, especialmente nos países desenvolvidos. Seria esperado, neste caso, que a proliferação de pesquisas na geografia humana direcionadas para a cultura propiciasse um engajamento mais sistemático com a teoria política. No entanto, talvez pelo contágio da geografia crítica, o poder tornou-se a referência ubíqua da nova geografia cultural (BARNETT e LOW, op.cit.).

296 Aprofundando ainda mais suas críticas, os autores destacam que os apontamentos acima chamam a atenção "para a preferência da geografia humana pela retórica da urgência do rigor explanatório, da mudança social, ou da relevância da decisão política, protelando a reflexão sobre questões normativas". Como conseqüência,

o tratamento geográfico da política é caracterizado pelo teoricismo, entendido [pelos autores] como tendência a deduzir o interesse político de interesses profundos, situados fora do processo político, para os quais o pesquisador acadêmico possui um insight privilegiado. Em resumo, os verdadeiros termos nos quais os geógrafos tem se engajado na discussão da política, justiça, cidadania e eleições tem alimentado uma persistente revogação da reflexão sobre os pressupostos normativos das instituições políticas e sobre os critérios básicos de julgamento político subsumido no processo democrático critério acerca do que é correto, do que é justo, do que é bom e acerca de como tornar o bom, o justo e o correto melhores (op.cit.:3).

O que é preciso explicitar neste debate é a propensão ao alinhamento da geografia humana crítica aos pontos de vista que conduzem à crítica da democracia representativa e à defesa da democracia radical ou direta, ou mesmo à irrelevância da democracia como questão. Cox (2004:38) é um bom exemplo deste último. Como um marxista fiel, suas análises tomam como ponto de partida que toda e qualquer mudança social é produto da relação entre a acumulação do capital e o trabalho, sendo neste caso o welfare state muito mais uma consequência do ciclo virtuoso da acumulação do capital no pós Segunda Guerra Mundial do que das lutas políticas dos sindicatos e dos partidos, em países europeus como a Inglaterra e a França, propiciadas pela democracia, que ele qualifica de uma quimera. Esta posição do geógrafo americano é coerente com a matriz marxista, muito mais preocupada com a economia capitalista e que nunca teve a política como um problema de eleição. A questão que deve ser feita porém, é, nas condições do mundo atual, quais os limites de aplicação ipsis litteris do modelo de acumulação elaborado por Marx para compreender a política?

No caso de alguns pós-marxistas das correntes da geografia humana crítica, mas bem menos radicais em relação à incorporação dos puros princípios materialistas, a crítica ao liberalismo con- 
duziu de modo natural à defesa da democracia radical ou sua vertente da democracia direta. Aqui o debate é também interessante. Ainda Barnett (2004), em outro texto, faz uma contundente crítica aos fundamentos ontológicos dessa perspectiva da democracia e, como foi apontado acima, chama a atenção para a sua adoção pelas correntes da geografia humanista e cultural como consequência da centralidade do lugar e da identidade como questões de predileção nestas correntes do pensamento geográfico. Esta me parece uma observação relevante na medida em que remete ao problema da escala incorporado à discussão conceitual da democracia.

Sintetizando esta parte, não há como escapar dos termos do debate impostos à disciplina pela vertente da geografia crítica anglo-saxã. Na análise dos argumentos que denotam a clivagem entre a democracia representativa e a democracia participativa é evidente a crítica aos sistemas políticos em geral e aos de representação parlamentar em particular e a idealização da democracia participativa e das comunidades de consenso, além da valorização dos formatos da democracia direta. Esta última, como já foi dito acima, fortemente influenciada pela perspectiva da valorização ontológica do lugar na geografia, inspira-se nas correntes filosóficas do "republicanismo" que entende

"a política como um complexo de vida ético (no sentido de Hegel), em que os membros de comunidades solidárias levam adiante essas relações de reconhecimento recíproco, de caráter mais ou menos natural, que se dão conta de sua dependência recíproca transformando-as em uma associação horizontal da vontade política, orientada para o entendimento ou para um consenso" (HABERMAS, 1995a:39-40).

Esta é também a perspectiva de Hanna Arendt (1998), de Claude Lefort (1983), de Jacques Rancière (2007), de Mouffe (2000) etc. que contribuem com os fundamentos da defesa da "democracia radical" e da crítica à democracia representativa na geografia. Mas, há dois problemas nesta posição: o primeiro, ressaltado por Frank Michelman (apud HABERMAS, 1995), é preciso acreditar que a comunidade de consenso seja composta por membros dotados de virtude, como queria Montesquieu (BIGNOTTO, 2010); o segundo é tomar a vontade geral rousseauniana como possibilidade prática em qualquer tipo de sociedade, o que em extremo conduz à perspectiva de Carl Smith (MOUFFE, 1992), ideólogo e ativista do nacional socialismo alemão comandado pelo partido nazista. Mas, finalmente, a experiência da democracia direta fora do seu berço grego, quando existe, é uma experiência possível em comunidades muito pequenas e pouco complexas aliás, bem de acordo com a proposta de Rousseau (1978).

Nesta revisão muito sumária foi possível indicar que a inclusão definitiva da democracia como questão na agenda da geografia contemporânea requer primeiro pensar a política em seu lugar espacial e social, ou seja, contida nos limites dos territórios e das sociedades nacionais, institucionalizados em termos de Estado de Direito, como apontado por Habermas (1995), indicado acima. Segundo, reconhecer o Estado como um recorte espacial significativo para a análise. Aqui a tese de Mann (1992) sobre a centralidade territorial do Estado como o pilar da autonomia do seu poder é instigante para a geografia e reforça nas suas análises as condições objetivas dos fundamentos territoriais da prática política (CASTRO, 2009). Terceiro, superar a prisão conceitual da geografia crítica e ir além dos limites explicativos da esfera econômica e da convicção de que os conflitos de interesses nas sociedades e no território se resolvem na solução dos conflitos produtivos que emergem do confronto das forças comandadas pela lógica da produção e da acumulação. Esta perspectiva, ao reduzir toda a ordem social à econômica, perde de vista as questões que se impõem à disciplina sobre a necessidade de compreender os conflitos distributivos, que surgem na sociedade e no território a partir de valores mais difusos inerentes à lógica da cidadania, da justiça e do direito que só se explicitam no campo da política e de suas instituições, ambas emergindo e se legitimando na arena dos conflitos de interesses que se organizam nos espaços das sociedades (CASTRO, 2005:11). É certamente da territorialidade da democracia que se trata aqui.

Mesmo se os três pontos indicados acima já frequentam uma parte da geografia francesa, inglesa e americana, eles são ainda quase ausentes e bastante polêmicos na geografia latino-americana, 
fortemente caudatária da corrente crítica, que a partir do final da década de 1970 incorporou à disciplina o paradigma marxista e o método materialista dialético. Este marco teórico conferiu privilégio à economia política em detrimento da política, negando a esta última qualquer fundamento na explicação dos fenômenos e processos sócio-espaciais (CASTRO, 2005:18). Neste ambiente acadêmico, a política como resultado de uma trama institucional é desqualificada porque vista como submetida às determinações do poder econômico ou mesmo a um poder reificado que como tal dispensa maiores explicitações.

Mesmo na geografia política o olhar para o território tinha em vista, de modo geral, o problema do poder e do controle, e o ponto de partida, naturalmente, não era aquele das condições originais da soberania estatal (RAFFESTIN,1993, SACK, 1986), apesar de o Estado ter sido, desde a origem da disciplina a escala territorial privilegiada. No entanto, seguindo a tradição ratzeliana, este privilégio, paradoxalmente, não deu a devida atenção àquilo que efetivamente consubstancia o aparato estatal: a territorialidade de suas instituições e seus atores políticos. Na disciplina, exceção deve ser feita ao trabalho de Gottmann (1973) sobre o significado do território que aponta para a crescente consciência e interesse no fator territorial.

Cabe lembrar aqui que a acepção de Michael Mann, indicada acima, sobre a centralidade territorial do Estado vai de encontro àquela de Entrinkin sobre a irrelevância do território no pensamento sociológico. Vale reforçar que a perspectiva de derivar o poder autônomo do Estado da sua centralidade territorial coloca para a geografia um desafio, na medida em que o território é a base daquele poder e implica a disciplina no debate sobre a relutância em aceitar esta autonomia, cuja ausência total é propugnada tanto pelos marxistas como pelos liberais e funcionalistas que reduziram o Estado à arena na qual se debatem as estruturas pré-existentes da sociedade civil ou pela aceitação de uma "autonomia relativa" pelos marxistas recentes (MANN, op.cit.:164). Se a argumentação a favor dessa autonomia é consistente, a democracia que tem no Estado seu lugar de contenção torna-se, ela mesma, um objeto de investigação importante para a geografia. E a significância do território amplia a intuição de Gottmann e adquire uma consistência nova, pois para além de arena, ele se torna a um fator chave para a institucionalidade da democracia, como bem perceberam os pensadores da antiguidade e aqueles do Iluminismo.

Concluindo esta primeira parte, o debate sobre a democracia nas ciências sociais confronta diferentes vertentes, desde a perspectiva do individualismo liberal, na tradição de Thomas Hobbes, John Locke ou Stuart Mill até as vertentes mais voltadas para a comunidade social, de inspiração rousseauniana, nas quais a vontade geral é o verdadeiro lócus da liberdade. Porém, qualquer que seja a perspectiva adotada, à geografia cabe contribuir com a análise da ordem espacial do processo democrático. Neste ponto, os apontamentos de Bussi são pertinentes, quando chama a atenção para: 1. o fato de a democracia ser por essência anisotrópica, o que requer análises comparativas; 2 . a necessidade de recortes espaciais para a democracia representativa; 3. a importância do voto como uma ação individual com implicação para a decisão coletiva e a urna como uma boa metáfora do território; 4. a igualdade de condições entre os cidadãos como condição da democracia que será sempre limitada em territórios desiguais; 5 . a necessidade de informações territorializadas, sendo o mapa um recurso importante (BUSSi, 2001:269-270).

\section{INSTITUICIONALIDADE E TERRITORIALIDADE DA DEMOCRACIA NO BRASIL}

A democracia tem freqüentado a geografia brasileira de modo mais explícito em temas como a territorialidade da representação política (MAGDALENO, 2010) ou na tentativa de compreender as estratégias territoriais de determinados atores sociais (FIANNI, 2008), ou na análise dos recursos institucionais de participação colocados à disposição da sociedade, como os conselhos e consórcios municipais (RODRIGUES, 2004; 2010; CASTRO, 2003), mas também na análise das experiências do orçamento participativo (SOUZA e RODRIGUES, 2004) ou dos problemas relativos aos proces- 
sos de emancipação municipal, que aliás tem merecido muita atenção nas pesquisas, (NORONHA 1997; TAVARES, 1992; PALMER, 2000; CATAIA, 2003) ou às questões federativas (CASTRO, WANIEZ e BURSTLEIN, 2002; CASTRO, 2007; RODRIGUES, 2006; CATAIA, 2003). Mas, há ainda a democracia que é subsumida nos temas como a cidadania (CASTRO, 2003; O'NEILL, 2004; NEVES, 2005) e o espaço público (GOMES et AL.2004; CASTRO, 2004; GOMES et AL., 2010; PINTO, 2011). Esta lista preliminar chama a atenção por apontar que o tema vem se impondo à geografia no país e que cada vez mais é inescapável abordá-lo, tendo em vista as muitas implicações para o território que resultam da complexidade dos sistemas políticos na atualidade.

$\mathrm{Na}$ realidade, todas essas perspectivas são importantes e interessantes, pois mesmo se a democracia não é tomada como um ponto de partida conceitual para as análises, estes temas supõem tanto a sua institucionalidade como a sua territorialidade. No entanto, a lista é ainda pequena, se comparada ao que o tema tem merecido na literatura geográfica européia e americana e nas ciências sociais no país, além das evidências dos impactos territoriais da experiência da democracia, especialmente após a constituição de 1988.

Na democracia representativa brasileira, os recursos de participação colocados à disposição da sociedade estão inscritos na Constituição Federal de 1988, cujo Artigo 14 define que

A soberania popular será exercida pelo sufrágio universal e pelo voto direto e secreto, com valor igual para todos, e, nos termos da lei, mediante: I - plebiscito; II - referendo; III - iniciativa popular.

Neste sentido, uma característica do formato institucional do sistema democrático no país é a existência de recursos de cunho participativo que vão além do momento de escolha dos representantes pelo voto. A outra, também constitucional, é a possibilidade de criação de conselhos municipais nos quais é prevista a participação de representantes da sociedade.

Para avançar nesta parte do trabalho, retomo o que já foi dito acima sobre o fato de a democracia ser tanto formato político como prática social e como tal contextualizada nos espaços e nos tempos das diferentes sociedades que a adotam. Neste sentido, algumas características da democracia no Brasil devem ser apresentadas à luz da polêmica sobre as dificuldades do sucesso da democracia em países pobres que alimenta os adeptos e os críticos da teoria da modernização estabelecida em 1959 por Lipset e mais recentemente revista por ele (LIPSET, 1994). Esta teoria apoiou-se na correlação entre indicadores de desenvolvimento econômico e o comportamento político. Apesar de ter sido muitas vezes demonstrada "a precariedade desse antiquado modelo causal, a ênfase no condicionamento econômico, quase determinístico, não desapareceu por completo do mundo acadêmico" (SANTOS, 2007:15). Ficamos então com a posição mais recente de Lipset que reconhece a necessidade de os governos manterem a legitimidade mantendo em ordem suas instituições econômicas assim como as políticas.

Indo mais além nesta discussã, recorro ao Wanderley Guilherme dos Santos, politólogo e renomado estudioso do sistema político brasileiro e sensível à história e ao espaço do país. Para ele, entre os axiomas básicos dos sistemas democráticos abandona-se a relação simplista entre democracia e renda para aquele que associa institucionalização democrática à institucionalização da competição política. A existência de real competição pelos postos de mando disponíveis e a certeza de que seus resultados serão respeitados constituem, em conjunto, um dos eixos fundamentais, o outro sendo a extensão da participação (SANTOS, 2007:39).

Analisando a competição eleitoral no Brasil, entre 1945 e 2006, o autor aponta que ocorreram 16 eleições gerais para preenchimento de vagas na Câmara dos Deputados e nas Assembléias Legislativas estaduais. Somando-se os pleitos nacionais e estaduais chega-se a 752 eleições em pouco mais de meio século de vida partidário-parlamentar, o que é raro na América Latina e temporalmente similar aos países da Organização para Cooperação e o Desenvolvimento Econômico (OCDE). Comparando com outros países verifica-se que, juntamente com o Chile e o Uruguai, o Brasil integra o grupo de países da América do Sul que experimentaram o menor número de inter- 
rupções institucionais durante o século XX. E mesmo se direitos civis e políticos foram afetados durante os 21 anos de autoritarismo militar (1964-1985), a competição eleitoral direta, apesar de submetida a regras constrangedoras naquele período, nunca foi interrompida (Santos, 2007:43-44). Ou seja, mesmo se limitado em suas funções e prerrogativas, o aparato institucional foi preservado, o que foi de grande valia para a retomada da normalidade política.

Outro dado importante da competição eleitoral aponta para a transição de uma condição inicial de sub-competição oligárquica antes de 1945 para a progressiva ampliação das condições em que todas as eleições estaduais tornaram-se competitivas a partir de 1990. "O megaeleitorado brasileiro explodiu os diques da competição confinada, o que significa mais opções de escolha pelo eleitor [...]" (op.cit.: 56) e o crescimento do eleitorado que passou de 16,2\% da população em 1945 para 69,11\% em 2006 é fundamental para a percepção desta transformação no país. O eleitorado em 2010 foi de 135.804.433 eleitores, ou seja, 69,94\% da população. Para o autor, este extraordinário processo de conversão do sistema eleitoral-partidário brasileiro, que passou de oligárquico a poliárquico pela inundação do mercado de votos, tornou impossível a continuidade oligárquica que se mantinha no ambiente de reduzida oferta de competição. Neste sentido, mantido o sistema proporcional, uma vez que são muitos os partidos, grande o potencial competitivo, elevadas as chances de vitória o grau de liberdade do eleitorado será preservado.

Nos sistemas de representação política, e o brasileiro não é diferente, a disputa política revela os interesses fundamentados nos territórios onde os atores sociais habitam, trabalham, produzem riquezas e lutam para se apropriar de parte dela. Neste sentido, os sistemas eleitorais, mesmo se genericamente agregados em duas grandes famílias: proporcionais e majoritários, cada uma delas divididas em subtipos, dificilmente se assemelham. As regras adotadas nas eleições são sempre elaboradas a partir das realidades concretas das sociedades e de seus espaços de vida as quais elas devem ser aplicadas (TAVARES, 1994; NICOLAU, 2004). E, nas democracias modernas, com duas câmaras, o Senado representa de modo igualitário as unidades da federação, ou seja, o território, e a Câmara dos Deputados representa a sociedade. A opção por sistemas de representação majoritário ou proporcional são, em última análise, tentativas de acomodar ou de reduzir o peso das diferenças no território.

O sistema eleitoral brasileiro é proporcional de lista aberta para a Câmara dos Deputados, para as Assembléias Legislativas estaduais e para as Câmaras de Vereadores municipais e majoritário para o Senado e para os cargos executivos - presidente, governador e prefeito. Este sistema tem duas singularidades: o eleitor tem a opção de votar apenas na legenda e a possibilidade de lista única de candidatos quando diferentes partidos estão coligados. O limite do número de candidatos por partido é generoso, o que aumenta a competitividade, inclusive dentro dos partidos.

Há na representação política uma tensão entre a representação do cidadão, que idealmente se resolveria na fórmula um homem um voto, e na do território que se resolve no Senado através das unidades políticas sub-nacionais. No entanto, no Brasil, o problema de encontrar uma equação para uma proporcionalidade ótima da representação parlamentar deve considerar algumas questões para a democracia: o primeiro é como obter uma proporcionalidade que, ao mesmo tempo controle a possibilidade da tirania da maioria, coincidentemente concentrada no centro-sul, juntamente com a maior parte das atividades econômicas e da renda, e que garanta os direitos da minoria e seja capaz de impedir o fortalecimento das oligarquias que historicamente dominam o cenário econômico e político das regiões mais pobres e o seu poder de veto nas mudanças que ameaçam a sua influência (Castro, 2005:174). Estas questões entram sempre na pauta quando se trata de discutir reformas políticas e surgem propostas sobre as vantagens dos sistemas majoritários frente à crítica da desproporção regional da representação no país.

Do ponto de vista do aprimoramento da democracia, no entanto, a perspectiva territorial da representação parlamentar brasileira, como apontado acima, incorpora a tensão entre impedir tanto o poder de veto das minorias oligárquicas e conservadoras que resistem, especialmente nas regiões 
mais pobres, como a hegemonia dos interesses das elites econômicas das regiões mais ricas. Afinal, as alianças entre interesses conservadores, tanto os oligárquicos da periferia como os hegemônicos do centro têm favorecido uma situação de persistentes disparidades regionais e de fortes injustiças espaciais, num país que já lidera o ranking mundial dessas desigualdades (CASTRO 1997b).

Todavia, o sistema de representação proporcional brasileiro, apesar das suas distorções históricas, tem permitido incorporar aos seus debates e decisões as grandes transformações econômicas e sociais das últimas décadas, cujo resultado mais importante tem sido a explosão do sistema oligárquico coronelista, no meio rural, e a redução do clientelismo carismático, no meio urbano. Mas, apesar de as eleições periódicas e regulares constituírem um meio, certamente o mais viável, embora não o único, para o controle dos representantes e para expressão dos representados em sociedades complexas, permanece o paradoxo da representação no Brasil, marcada ainda pelo caráter fortemente elitista da nossa tradição política. É nestes dois contextos que a discussão atual sobre a adequabilidade da estrutura representativa no país pode e deve ser remetida às disputas econômicas e políticas regionais.

A lição extraída da experiência do século XX é a inevitabilidade do sistema representativo e a necessidade de repensá-lo sempre para torná-lo compatível com os ideais democráticos e de justiça, tanto social como espacial. Porém, os limites operacionais do sistema não deixarão nunca de constituir um parâmetro obrigatório. Neste sentido, sendo enfatizada a composição de um corpo legislativo, assume importância determinar se o sistema eleitoral garante ou não a correspondência entre esse corpo e a nação como um todo. É preciso reconhecer que o perfil do Congresso nacional é ainda elitista, quando comparado seus níveis de escolaridade e renda com a média brasileira. No entanto, as mudanças tem sido progressivas, quando se compara com os corpos legislativos do passado.

Há ainda, porém, um longo percurso para o aperfeiçoamento do sistema, pois mesmo na atualidade, quando a incorporação à cidadania política de todos os segmentos sociais finalmente foi alcançada com a extensão do voto aos analfabetos, determinada pela Constituição de 1988, a legislação eleitoral permite que haja uma ampla margem de apropriação indébita dos votos através de transferências não autorizadas. Na prática isto significa a manutenção de amplas margens de exclusão da vontade do eleitor em todas as unidades políticas da federação.

Análises do processo eleitoral tem avaliado os efeitos perversos das legislações eleitorais brasileiras sobre a real proporcionalidade entre as escolhas do eleitorado e a composição da representação. Santos (1995) destaca que determinados aspectos da legislação eleitoral brasileira - tais como o sistema de listas abertas com grande número de candidatos por partido e a prática de coligações eleitorais - distorcem acentuadamente os princípios da representação proporcional enquanto tal. Também Lessa (1996) em sua pesquisa sobre os desvios dos votos, e conseqüentemente da vontade do eleitor no Rio de Janeiro, possibilitados pela legislação, indica o caráter rarefeito e distorcido da representação e o alcance real da exclusão de cidadãos do processo de manufatura desta representação. No entanto, deve ser ressaltado que apesar das dificuldades apontadas o desenho do sistema de representação proporcional do Brasil tem incorporado todo o espectro de interesses de grupos, de minorias ou de tendências na sociedade, em todo o território (NUNES, NOGUEIRA e TAFNER, 1995).

É preciso considerar que a concentração de população e de atividades econômicas nas unidades da federação no centro-sul é o reflexo da concentração das atividades econômicas e do poder de decisão nestas áreas, desde a independência no século XIX. Porém, o sistema representativo de base territorial supõe que as conexões eleitorais dos representantes com seus lugares, mesmo nos mais atrasados, possibilitem condições mais favoráveis à preservação dos graus de liberdade em relação à competição nos estados. Neste sentido, tão desejável quanto melhorar a legislação para aproximar mais o resultado das eleições com a vontade do eleitor é estabelecer as condições para que o sistema político continue a favorecer o processo de interiorização do desenvolvimento. $\mathrm{O}$ que já vem ocorrendo progressivamente desde as últimas décadas, criando novas atividades, novas 
lideranças e mais participação, estas sim os melhores antídotos contra os tradicionais vícios do poder conservador na periferia.

A representação territorial brasileira, apesar da sub representação de São Paulo e da sobre representação dos estados das Regiões Norte e Centro-Oeste, tem dado voz à periferia e tem permitido que suas demandas legítimas, e não apenas barganhas de interesses pessoais, cheguem ao centro de poder. É preciso, pois estar atento à incorporação da periferia ao processo de desenvolvimento com todas as conseqüências possíveis para a reorganização do território e para a inclusão social de segmentos até então marginalizados.

Outra questão debatida e criticada no sistema proporcional brasileiro é o grande número de partidos políticos e os riscos para a governabilidade. Tanto governos como oposição convergem na ácida crítica ao sistema político e suas normas como: o voto compulsório, o sistema proporcional, o regime presidencialista, a inexistência de cláusulas de barreiras para os partidos pequenos, a volubilidade do comportamento parlamentar e o financiamento privado das campanhas eleitorais (SANTOS, 2007:65-66). No entanto, ao contrário do sistema majoritário, sempre lembrado quando reformas políticas são propostas, o sistema proporcional tem se mostrado o mais adequado a sociedades em processo de mudanças.

Dentre as críticas ao sistema proporcional presidencialista encontra-se a relacionada ao risco de ingovernabilidade devido à fragmentação partidária. No entanto, como o custo político da incerteza ou da não decisão pode ser, na prática, muito elevado, o sistema brasileiro adota a coligação como solução. Neste sentido, mesmo se muitos partidos se apresentam - foram 29 em 2006, por exemplo - apenas 5 partidos ocupavam 55\% das cadeiras na Câmara dos Deputados e 8 partidos não elegeram nenhum deputado. Ou seja, 21 partidos conseguiram eleger representantes e destes 9 elegeram menos de 10 representantes. Vale observar que estes partidos "nanicos" em geral situam-se nos extremos do espectro ideológico, de direita ou de esquerda, e tendem a se agregar à maioria, por maior proximidade ideológica ou para obtenção de vantagens que reforcem sua conexão eleitoral, ou seja, através da obtenção de recursos para seus redutos de votos.

Outra característica do sistema eleitoral do país é a possibilidade de elevados índices de renovação de seu corpo de representantes a cada eleição, o que reflete a elevada competitividade do sistema. Entre 2002 e 2006 o índice de renovação da Câmara de Deputados foi de 46\% para a média do país, com uma diferença regional de $62,7 \%$ para a Região Sudeste - mais urbanizada e onde se concentra a maior parte da riqueza do país - e 41\% para a Região Centro-Oeste e 46,3\% para a Região Nordeste. Apesar de diferenças importantes entre estas duas últimas, ambas guardam redutos conservadores de origem rural.

Ainda com relação aos padrões de competição política, Carvalho (2003) encontrou diferenças regionais que merecem consideração e que refletem a complexidade do país. Mesmo se, como já foi afirmado acima, o sistema possibilitou o enfraquecimento ou mesmo, em alguns casos, o quase desaparecimento das oligarquias tradicionais, este processo não está concluído nem é linear. Encontra-se ainda em alguns estados da Região Nordeste, reduto mais antigo da elite política conservadora, os padrões mais elevados de concentração de votos. Nesta Região há ainda o domínio de grupos políticos tradicionais que controlam as bases partidárias em alguns estados. Mesmo se importantes bolsões de pobreza resistem na Região e os índices de escolaridade são mais baixos, transformações vêm ocorrendo gradualmente a cada processo eleitoral.

\section{CONSIDERAÇÕES FINAIS}

A expansão das democracias representativas pelo mundo desafia a geografia a engajar-se na compreensão da territorialidade e das escalas desse fenômeno político. Este não deve ser um campo restrito à ciência política e requer uma reflexão sobre os conteúdos explicativos dos territórios. Especialmente frente ao fenômeno ainda mais novo das democracias de massa cujas conseqüências 
ainda requerem ser avaliadas. A democracia brasileira, por sua vez, passa por um momento crucial de massificação, consolidação e de estabilidade das suas instituições políticas. O sistema eleitoral multipartidário de representação proporcional, apesar das críticas aos seus desvios, não tem sido obstáculo ao ritmo acelerado das mudanças social e econômica no país e ao tamanho e complexidade do seu território.

Neste sentido, a nossa democracia deve ser compreendida a partir dos seus contextos institucionais, histórico e sociais que adquirem plenitude e visibilidade no território. A agenda da disciplina ainda não responde aos temas que o sistema político, as possibilidades de participação popular no sistema decisório e os aparatos institucionais tornados possíveis com a nova Constituição colocam para as pesquisas. O debate contemporâneo sobre o sistema político brasileiro convoca então a geografia a colocar o espaço, sua materialidade e institucionalidade, como um dado essencial, no qual a cidadania se concretiza como prática no território. A conexão eleitoral, por exemplo, expressão plena da territorialidade do sistema representativo vincula o voto à voz e à ação. As escalas políticas características do nosso federalismo estão a requerer uma análise que considere as possibilidades e os limites de cada uma delas. A interiorização da população, das atividades econômicas e dos conflitos de interesses inerentes a esta dinâmica sócio-espacial tem sido acompanhada pela demanda por novos recortes territoriais, continentes de novas densidades institucionais, que se expressam em projetos de novas divisões do território nacional, tanto na escala das unidades da federação como naquela dos municípios. A geografia do voto, expressão plena das estratégias territoriais de diferentes atores políticos e sociais nas três escalas do nosso federalismo tem sido, no país um campo quase exclusivo de cientistas políticos o que convoca a geografia brasileira a retornar a André Siegfried $(1913,1949)$ e efetivamente se apropriar dele. Esta lista de possibilidades está evidentemente incompleta, mas me parece um ponto de partida interessante para o debate.

Finalmente, voltando à proposta do título desta mesa, se admitirmos com os filósofos marxistas contemporâneos Claude Leffort (1983) e mais recentemente Slavoj Zizek (2011) que a democracia é ainda o melhor caminho para mudanças que podem chegar a ser radicais, porém não necessariamente velozes como querem alguns espíritos voluntaristas, talvez nostálgicos das Revoluções dos Séculos XVIII e XX, a geografia pode efetivamente contribuir para a discussão de um projeto político para o Brasil que seja tanto socialmente como territorialmente justo e inclusivo, o caminho mais seguro e duradouro para a mudança social.

\section{REFERÊNCIAS BIBLIOGRÁFICAS}

ARENDT, H. O que é política. Rio de Janeiro: Bertrand Brasil, 1998.

BARNETT, C. Deconstructing radical democracy: articulation, representation, and being-with-others. Political Geography 23, 2004. p. 503-528

BARNETT, C.; L O W, M. Geography and Democracy: An Introduction. In: B A R N E T T, C.; L O W, M. (Edts) Spaces of democracy. Londres, Sage, 2004.

BARNETT, C. Theorising democracy geographically. Geoforum, 39 (5), 2008. p. 1637-1640.

BELL, J. E.; STAEHELI, L. A. Discourses of diffusion and democratization. Political Geography, 20, 2001. p. 175-195.

BIGNOTTO, N. As aventuras da virtude. As idéias republicanas na França no Século XVIII. São Paulo: Companhia das Letras, 2010.

BOBBIO, N. Estado, governo e sociedade. Para uma teoria geral da política. São Paulo: Paz e Terra, 1985. BOBBIO, N. Igualdade e justiça. Rio de Janeiro: Ediouro, 1995.

BRAGA, D. F. Pentencostalismo e política: uma geografia eleitoral dos candidatos ligados à Igreja Universal do Reino de Deus no Município do Rio de Janeiro. Dissertação (Geografia) - Universidade Federal do Rio de Janeiro, 2008.

BUSSI, M. Géographie, démocratie et participation: explication d'une distance, arguments pour un rappro- 
chement. Géocarrefour, 76 (3), 2001. p. 265-272.

CASTRO, I. E. O problema da escala. In: Geografia conceitos e temas.1 ed. Rio de Janeiro: Bertrand Brasil, 1995, p. 117-140.

CASTRO, I. E.; WANIEZ, P.; BURSTLEIN, V. Les finances locales comme révélateur de la croissance et des blocages territeriaux au Brésil. Problèmes d'Amerique Latine, 45, Paris, 2002. p. 53-72.

CASTRO, I. E. Instituições e territórios. Possibilidades e limites ao exercício da cidadania no Brasil. Florianópolis, GEOSUL, v.19, 2003. p.16-32.

CASTRO, I.E. Espaços públicos: entre a publicidade e a política. ALCEU, v.4, n.8, 2004. p. 141-155.

CASTRO, I. E. Décentralisation, démocratie et représentation législative locale au Brésil. Espace Politique, v.3, 2007. p.60-73.

CASTRO, I. E. O território e o poder autônomo do Estado. Uma discussão a partir da teoria de Michael Mann. In: MENDONÇA, F.; LOWEN-SAR, C. L.; SILVA, M. (Orgs) Espaço e Tempo. Complexidade e desafios do pensar e do fazer geográficos. Curitiba: Ademadan, 2009.

CATAIA, M. A. A Alienação do Território. O Papel da Guerra Fiscal no Uso, Organização e Regulação do Território Brasileiro. In: SOUZA, M. A. A. (Org.). Território Brasileiro. Usos e Abusos. 1 ed. Campinas: Edições Territorial, , v. 1, 2003. p. 397-407.

COX , K. R. Spaces of dependence, spaces of engagement and the politics of scale or: looking for local politics. Political Geography, Volume: 17, Issue: 1: 1-23, 1998.

COX, K. R. Globalization, the class relation and democracy. GeoJournal, 60: 31-41, 2004.

ENTRIKIN, J. N. Lieu, culture et démocratie. Cahiers de géographie du Québec, vol. 41, n 114, 1997, p. 349-356.

ENTRIKIN, J. N. Le langage géographique dans la théorie démocratique. In: LÉVY, J.; LUSSAULT, M. 304 Logiques de l'espace, esprit des lieux. Paris: Belin, 2000.

GOMES, P. C. C.; BERDOULAY, V. Introduction: Image et espace public: la composition d'une scène. Géographie et Cultures, v. 73, 2010. p. 3-6.

GOTTMANN, J. The significance of territory. University Press of Virginia, 1973.

HABERMAS. J. Diagnósticos do tempo. Seis ensaios. Rio de Janeiro: Tempo Brasileiro, 2005.

HABERMAS. J. Três modelos normativos de democracia. São Paulo: Lua Nova, n.36, 1995.

JUD, D. The case of missing scales: a commentary on Cox. Political Geography, v. 17, Issue: 1: 1-23, 1998.

KARIEL, Henry S. (Editor) Frontier of democratic theory. Random House: 1970.

LEFORT, C. A invenção democrática. Os limites da dominação totalitária. São Paulo: Brasiliense, 1983.

LESSA, Renato. A sombra da representação. Monitor Público, Ano 3, n. 10, 1996. p. 11-20.

LIJPHART, A. As democracias contemporâneas. Lisboa: Gradiva, 1989.

LIMA, M. H. P. O processo de emancipação municipal do estado do Espírito Santo. Programa de Pós-Graduação em Geografia da UFRJ, 2000.

MAGDALENO, F. S. A territorialidade da representação política. São Paulo: Annablume, 2010.

MANN, M. O poder autônomo do Estado: suas origens, mecanismos e resultados. In: HALL, John (Org.) Os Estados na história. Rio de Janeiro: Imago, 1992..

MASSEY, Doreen. Thinking radical democracy spatially. Environment and planning: Society and space, 13, 1995. p. 283-288.

MOUFFE, C. Penser la démocratie moderne avec, et contre, Carl Schmitt. Revue Française de Science Politique, v. 42, n. 1, 1992.

MOUFFE, Chantal. The Democratic Paradox. Londres/Nova York: Verso, 2000.

NEVES, F. O. A questão do lixo como uma dimensão da cidadania. Programa de Pós-Graduação em Geografia - UFRJ, 2005.

NICOLAU, J. Sistemas eleitorias. Rio de Janeiro: FGV, 2004.

NORONHA, R. A territorialidade da fragmentação político-administrativa do estado do Rio de Janeiro. Programa de Pós-Graduação em Geografia, 1997. 
O'LOUGHLIN, J. Geography and democracy: the spatial diffusion of politial and civil rights. In: KNIPPENBERG, H.; DIJKINK, G. (Eds) The territorial factor: political geography in a globalising world. Amsterdan, Vossiuspers. 2001. p. 77-96.

O’NEILL, M. M. V. C. As Bases Territoriais Institucionais: Novas Configurações no Espaço Nordestino. Tese (Geografia) - Universidade Federal do Rio de Janeiro, 2004.

PINTO, A. M. A. A construção dos espaços públicos em Bogotá e no Rio de Janeiro: uma análise comparada. Tese de Doutorado, Programa de Pós-Graduação em Geografia, UFRJ, Rio de Janeiro, 2011.

RAFFESTIN, C. Por uma geografia do poder. São Paulo: Ática, 1993.

RANCIÈRE, J. La haine de la démocratie. Paris: La Fabrique, 2005.

RAWLS, J. Uma teoria de justiça. Brasília: Editora UNB, 1971.

RAWLS, J. O direito dos povos. São Paulo: Martins Fontes, 2004.

RODRIGUES, J. N. O Município como escala de gestão no Brasil contemporâneo. Monografia, Rio de Janeiro, Universidade Federal do Rio de Janeiro, 2004.

RODRIGUES, J. N. As transferências intergovernamentais de recursos do FPM e do ICMS como estratégias de equilíbrio espacial. Dissertação (Geografia) - Universidade Federal do Rio de Janeiro, 2006. ROUSSEAU, J.-J. Do contrato Social. São Paulo: Abril Cultural, 1978.

SACK, R. D. Human Territoriality: its theory and history. Londres: Univ. Cambridge Press, 1986.

SANTOS, W. G. Paradoxos do liberalismo. Rio de Janeiro: Revan, 1999.

SANTOS, W. G. dos. O paradoxo de Rousseau: uma interpretaçao democrática da vontade geral. Rio de janeiro: Rocco, 2007.

SIEGFRIED, A. Tableau politique de la France de l'Oest. Paris: Armand Colin, 1913.

SIEGFRIED, A. Géographie électorale de l'Ardechesous la Troisième Republique. Paris: Armand Colin, 1949.

SMITH, Graham. Teoria política e geografia humana. In: GREGORY, D. MARTIN, R.; SMITH, G. Geografia humana. Rio de Janeiro: Zahar, 1996. p. 65-89.

SOUZA, M. L. e RODRIGUES, G.B. Planejamento urbano e ativismos sociais. São Paulo: Editora Unesp, 2004.

SOUZA, M. A.A.; CATAIA, M. A.; TOLEDO JUNIOR, R. Território, lugar e poder: a expressão territorial do voto no Ceará. Sobral: Edições UVA, 2002.

STOKE, K. Human geography and the contextual politics of substantive democratization. Progress in Human Geography, 33 (6), 2009. p 739-742

TAVARES, J. G. Sistemas eleitorais nas democracias contemporâneas. Rio de Janeiro: Relume-Dumará, 1994.

TAVARES, M. G. C. O município no Pará, a dinâmica territorial - Município de São João do Araguaia. Programa de Pós-Graduação em Geografia-UFRJ, 1992.

TOURAINE, A. Poderemos viver juntos? Petrópolis: Vozes, 1998.

Trabalho enviado em agosto de 2011

Trabalho aceito em outubro de 2011 